\title{
Need for Improvement of Medical Records
}

\author{
Mishra AK, ${ }^{1}$ Bhattarai $S,{ }^{2}$ Bhurtel $\mathrm{P},{ }^{2}$ Bista NR, ${ }^{2}$ Shrestha $\mathrm{P},{ }^{2}$ Thakali K, ${ }^{2}$ Banthia $\mathrm{P}_{,}{ }^{2}$ Pathak $\mathrm{SR}^{3}$ \\ 'Liver Unit, Bir Hospital National Academy of Medical Science, Kathmandu, Nepal, ${ }^{2} x e n o M E D$ Foundation, Kathmandu, Nepal, \\ ${ }^{3}$ Mt. Everest Hospital, New Baneshwor, Kathmandu, Nepal
}

\section{ABSTRACT}

Introduction: A medical record is a systematic documentation of a patient's medical history and care for legal and future use. A poor quality medical record can negatively affect patient care and safety. The study aims to assess the adequacy of medical records in Bir Hospital, a central hospital.

Methods: A cross-sectional study was conducted by analyzing consecutive discharge summaries of patients admitted during a 6 month period in a single unit of a tertiary care center. The discharge summary format of the hospital was taken as the standard and evaluation for adequacy of data entered was assessed. Descriptive statistics were used to analyze various statistical discrepancies.

Results: Patient's condition at discharge was missing in 86 (66.15\%). Patient's address was missing in $21(16.1 \%)$ cases. Almost all the discharge sheets lacked mailing address. Total $96(73.8 \%)$ had use of abbreviations diagnosis. Age and sex were missing in $1(0.76 \%)$. Doctor's signature was illegible in $103(79.3 \%)$ and missing in $2(1.5 \%)$ summaries. Doctor's name and their level/position were missing in $118(90.76 \%)$ and $125(96.1 \%)$ respectively. Total 126 patients (96.9\%) were not given any instructions on discharge.

Conclusions: The discharge summaries analyzed were seen to be inadequate especially in documenting course during the hospital stay, condition at discharge, appropriate instructions and the treating physician's details. These can probably be addressed by introducing electronic medical records if feasible. Otherwise, the discharge summary should be standardized and doctors should be trained to write legible, complete discharge summaries.

Key Words: discharge, hospital, records, summaries

\section{INTRODUCTION}

A medical record is a systematic documentation of a patient's medical history and care which is compiled and stored by the health care providers. ${ }^{1}$ A discharge summary transfers important clinical information from inpatient to outpatient settings and between hospital admissions and is important in maintaining the continuity of care. ${ }^{2,3}$ As per the Joint Commission on the Accreditation of Healthcare Organizations, it should contain the following components: 1 . reason for hospitalization, 2. significant findings, 3. procedures and treatment provided, 4. patient's discharge condition, 5. patient and family instructions (as appropriate), 6 . attending physician's signature ${ }^{4}$ It serves as a reliable documentation of patient's medical history.

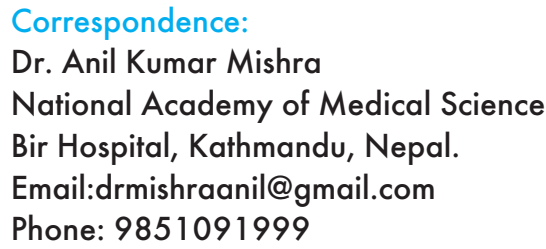


Medical records serve as documented proof in case any legal issues regarding quality of treatment or negligence arise. These records form reliable and easily accessible data sources for health policy planning. ${ }^{5} \mathrm{~A}$ poor quality discharge summary can negatively affect patient safety. ${ }^{6}$ This study aims to assess the adequacy of medical records by the health professionals, prepared by the hospital.

\section{METHODS}

This cross-sectional study was conducted by analyzing discharge summaries of patients admitted from April 13, 2008 to October 16, 2008 to the Liver Unit of Bir hospital, a central tertiary care hospital, Nepal. Institutional approval was taken for medical records. The discharge summary format of Bir Hospital was taken as the standard in its premises and evaluation was done for completeness of the information entered (Table 1).

Table 1. Subheading under which completeness was checked

\begin{tabular}{l} 
Demographic details \\
Name, Age, Sex, Address \\
\hline Hospital details \\
Inpatient number, Bed number, Unit, Date of \\
admission, Date of discharge \\
Diagnosis \\
Abbreviations used, whether standard or not, \\
Legibility \\
Case details \\
History, Physical examination, Investigation, \\
Course in hospital with treatment given, \\
Condition at discharge, Treatment at discharge, \\
Instructions, Follow up \\
Doctor's details \\
Signature- legible or not, Name, Position
\end{tabular}

Legibility was defined as capable of being read and rated by three different people. Non standard abbreviation was defined as one which could not be found in standard medical literature.

Descriptive statistics were used to analyze various statistical discrepancies. The data was entered and analyzed using Microsoft Office EXCEL 2007.

\section{RESULTS}

A total of 130 discharge summaries were obtained. Age and sex were missing in $1(0.76 \%)$ of the patient. Patient's address was missing in $21(16.1 \%)$ cases.
None of the summaries contained the full mailing address (Table 2).

Table 2. Demographic details

\begin{tabular}{ll}
\hline Demographic details & Frequency missing (\%) \\
\hline Name & $0(0 \%)$ \\
Age & $1(0.76 \%)$ \\
Sex & $1(0.76 \%)$ \\
Address & $21(16.1 \%)$ \\
\hline
\end{tabular}

About 4 (3.076\%) patients' bed number was not present. Total $7(5.38 \%)$ of discharge sheet failed to mention the unit. Date of admission (DOA) and date of discharge were missing in $2(1.53 \%)$ and $1(0.76 \%)$ summaries respectively (Table 3 ).

Table 3. Hospital details

\begin{tabular}{ll}
\hline Hospital details & Frequency missing (\%) \\
\hline Inpatient number & $0(0 \%)$ \\
Bed number & $4(3.8 \%)$ \\
Unit & $7(5.38 \%)$ \\
Date of admission & $2(1.53 \%)$ \\
Date of discharge & $1(0.76 \%)$ \\
\hline
\end{tabular}

Abbreviations were used in diagnosis in 96 (73.8\%) summaries (Table 4).

Table 4. Diagnosis and use of abbreviations

\begin{tabular}{ll}
\hline Diagnosis and abbreviations & Frequency (\%) \\
\hline Diagnosis & $130(100 \%)$ \\
Abbreviations used & $96(73.8 \%)$ \\
Legibility & $130(100 \%)$ \\
\hline
\end{tabular}

Six $(4.61 \%)$ and $4(3.076 \%)$ discharge summaries had no clinical history and physical examination findings respectively. Investigations and results were mentioned in all summaries. Although, the treatment during the hospital stay was present in all summaries, it included the drug treatment given but failed to mention the patient's improvement or deterioration in all but 6 cases. The patient's condition at discharge was missing in $86(66.15 \%)$ summaries. Total $6(4.61 \%)$ summaries had no advice on when to follow up. Total 126 patients $(96.9 \%)$ were not given any instructions, like abstain from alcohol in cases with Alcoholic Liver Disease, on discharge (Table 5). The date on which the discharge summary was written was missing in $(24.6 \%)$ cases. 
Table 5. Case details and missing frequency

\begin{tabular}{lc}
\hline Case details & Missing Frequency (\%) \\
\hline History & $6(4.61 \%)$ \\
Physical examination & $4(3.07 \%)$ \\
Investigation & $0(0 \%)$ \\
Course in hospital & $6(4.61 \%)$ \\
Condition at discharge & $86(66.15 \%)$ \\
Treatment at discharge & $6(4.61 \%)$ \\
Instructions & $126(96.9 \%)$ \\
Follow up & $6(4.61 \%)$ \\
\hline
\end{tabular}

Two $(0.02 \%)$ summaries lacked the signature of the doctor writing the summary. Only 27 (20.7\%) summaries had legible signatures. Doctor's name and level/position were missing in $118(90.76 \%)$ and 125 (96.1\%) respectively (Table 6 ).

Table 6. Doctor's details and missing frequency

\begin{tabular}{lc}
\hline Doctor's details & Missing frequency (\%) \\
\hline Signature missing & $2(0.02 \%)$ \\
Legibility & $27(20.7 \%)$ \\
Name missing & $118(90.76 \%)$ \\
Position & $125(96.1 \%)$ \\
\hline
\end{tabular}

Total of 65 (50\%) patient's sheet did not include the name of the doctors under whom they were treated.

\section{DISCUSSION}

Medical records should be should be clear, complete, organized, accessible as they play an important role in the future treatment especially continuity of care and planning health policy. ${ }^{2,5}$ It has an important role in case of medico legal cases. As observed, address was missing in 21 discharge summaries. None of contained the full mailing addresses. This precludes any opportunity to contact the patient for follow up and future contact for any reason.

In some discharge summaries basic hospital details like bed number, unit were missing. The study found almost $75 \%$ diagnosis with abbreviations, which is more as comparison to $27 \%$ in an emergency based study conducted in India. ${ }^{7}$

It was surprising to note that clinical details like history and physical examination were missing in 6 and 4 summaries respectively which was higher than a similar study conducted in Canada. ${ }^{8}$

The course in the hospital mostly contained the medications administered but lacked any documentation of patient's improvement or deterioration during the hospital stay. Thus there was no information on how the patient responded to treatment when a new center/ doctor read the summary. Surprisingly, the condition of discharge was not mentioned in 86 cases. It has been identified as one of the essential components of a good medical discharge. ${ }^{4}$ It is of extreme importance as it helps prevent any legal hassles in case a stable patient deteriorates after discharge from the hospital.

The discharge medications were missing in 6 . The dosage of medications and duration was mentioned in all. This was better in comparison to the Canadian study. ${ }^{8}$

Total 126 cases lacked any instruction which, if appropriate, has been identified as an essential component of a discharge summary. ${ }^{4}$ It is especially important in this study as majority of patients suffered from either alcoholic or infectious liver disease in which specific instructions such as avoid alcohol are very important. Even if the instructions were given verbally, there has been no documentation. Besides studies have shown the recall of verbal instructions can be poor. ${ }^{7}$

It was found that the doctor's details entered at the end of the sheet were grossly lacking. Only 27 of signatures were legible, 118 summaries had no doctor's name, 125 didn't mention the position of the doctor writing the summary. Total of 65 patient's sheet did not include the name of the consultant under whom the treatment was done and in the $50 \%$ that did, almost $80 \%$ had the name of the consultant in an abbreviated format. The doctor's details especially signature is essential ${ }^{4}$ in a discharge summary. It aids doctor to doctor communication, follow-up and is important in medicolegal cases. Also, a patient has a full right to knowledge of who the treating physician is, which has not been addressed here.

The results show that the discharge summaries are inadequate in important areas like hospital, doctor's details and other details like course in the hospital, condition at discharge and appropriate essential instructions. During the study it was found that the summaries were not always uniform, complete and the information was sometimes difficult to understand and retrieve. The findings are corroborated by studies which find that paper records can be illegible, incomplete and poorly organized, making it difficult to ensure quality of care. $^{9}$ This is in contrast to electronic medical records that provide documentation which are $40 \%$ more complete and $20 \%$ more faster to retrieve. ${ }^{10}$ There are more benefits of EMR in comparison to traditional paper based medical record like improved patient care through efficient access to accurate records; improved office efficiency; easy data retrieval from more 
legible, understandable records and potential financial benefit. ${ }^{10,12-3}$ Also these records form reliable and easily accessible data sources for health policy planning. They have also been shown to be conducive to more complete and accurate documentation by health care professionals. ${ }^{11}$ Interestingly, one study showed that doctors using paperless records were able to recall more advice given to patients. ${ }^{12}$ Therefore, it seems for a tertiary care center like Bir hospital, the time for switching to electronic medical record system has come.

There are a few shortcomings of EMR like data hacking, requirement of a trained person and major investment which needs to be addressed while implementing Electronic Medical Record System. ${ }^{13}$

If switching to an EMR system is not feasible at present, the discharge summary should be standardized; doctors should be trained to write legible and complete discharge summaries. The details of the treating physician should not be omitted.

The study design being retrospective is one of the limitations of the study. Also, the sample in not random and consists of all cases admitted limited to a certain period of time. Since a basic checklist for the presence or absence of certain factors was utilized the study fails to scrutinize the quality of details written in the discharge summary. The fact that the study was entirely based on discharge summaries and there was no comparison with the patient's file prevents any comment on whether important details have been missed in the discharge summaries.

\section{CONCLUSIONS}

The discharge summaries analyzed were seen to be inadequate especially in documenting course during the hospital stay, condition at discharge, appropriate instructions and the treating physician's details which are an essential part of a good discharge summary. Deficiencies were also found in other areas like demographic details. The lack of legibility of the doctor's signature and information about the attending physician needs to be addressed. Electronic medical records can be a possible solution as they have been found to be more complete, legible, understandable, efficient and accessible than paper medical records. May be it is time to switch to electronic medical records in a tertiary center like Bir Hospital. If it is not feasible at present, the discharge summary should be standardized; doctors should be trained to write legible and complete discharge summaries including condition at discharge, instructions and details of the treating physician.

\section{REFERENCES}

1. Wikipedia. Medical record. [Online]. [cited 19 May 2009]; Available from URL: http://en.wikipedia.org/wiki/ Medical_records

2. Rao P, Andrei A, Fried A, Gonzalez D, Shine D. Assessing quality and efficiency of discharge summaries. Am J Med Qual 2005 Nov-Dec;20(6):337-43.

3. van Walraven C, Rokosh E. What is necessary for high-quality dischargesummaries? AmJMedQual1999Jul-Aug;14(4):160-9.

4. Joint Commission on the Accreditation of Healthcare Organizations. Standard IM.6.10, EP 7 Website. [Online]. [Cited 31 Mar 2008]; Available from URL: http://www. jointcommission.org/NR/rdonlyres/A9E4F954-F6B5-4B2D9ECF-C1E792BF390A/0/D_CurrenttoRevised_DC_HAP.pdf

5. Häyrinen K, Saranto K, Nykänen P. Definition, structure, content, use and impacts of electronic health records: a review of the research literature. Int J Med Inform 2008 May;77(5):291-304.

6. Myers JS, Jaipaul CK, Kogan JR, Krekun S, Bellini LM, Shea JA. Myers JS, Jaipaul CK, Kogan JR, Krekun S, Bellini LM, Shea JA. Acad Med 2006 Oct;81(10 Suppl):S5-8.

7. D V NN, Rajavelu P, Rajagopalan A. Pre-formatted written discharge summary-a step towards quality assurance in the emergency department. Int J Emerg Med 2008 Dec;1(4):321-5.

8. van Walraven C, Weinberg AL. Quality assessment of a discharge summary system. CMAJ 1995 May 1;152(9):1437-42.

9. Young AS, Sullivan G, Burnam MA, Brook RH. Measuring the quality of outpatient treatment for schizophrenia. Arch Gen Psychiatry 1998;55:611-7.

10. Tsai J, Bond G. A comparison of electronic records to paper records in mental health centers. Int J Qual Health Care 2008 Apr;20(2):136-43.

11. Häyrinen K, Saranto K, Nykänen P. Definition, structure, content, use and impacts of electronichealth records: a review of theresearchliterature. IntJ Med Inform2008 May;77(5):291-304.

12. Hippisley-Cox J, Pringle M, Cater R, Wynn A, Hammersley V, Coupland C, Hapgood R, et al. The electronic patient record in primary care--regression or progression? A cross sectional study. BMJ 2003 Jun 28;326(7404):1439-43.

13. Lorenzi NM, Kouroubali A, Detmer DE, Bloomrosen M. How to successfully select and implement electronic health records (EHR) in small ambulatory practice settings. BMC Med Inform Decis Mak 2009 Feb 23;9:15. 